\title{
0 Exercício da Sexualidade na Adolescência. I. Aspectos Biopsicossociais
}

\begin{abstract}
Nelso Vitiello
Is éri eixas Cheque Co eição ${ }^{2}$

adoles ia o pree dida o o fase pe uliar de tra sição biopsi osso ial é u período ara terizado pelas tra sfor ações biológi as e pela bus a da defi ição de u papel so ial deter i ado pelos padrões ulturais do eio. Essa o eituação exarada do e i ário Lati o- eri a o sobre a aúde do doles e te ha a a ate ção para a o plexidade do proble a. De fato os aspe tos biológi os estão de tal a eira i bri ados o aqueles de fu do psiosso ial que a i terdepe d ia e a i teração e tre eles é o pleta. Por esse otivo é $\mathrm{i}$ possível o pree der be os aspe tos ligados ao exer í io da sexualidade e sobre eles i fluir se $u$ a o pree são global da adoles ia. Tor a-se assi evide te que ape as o o etodologia de abordage pode-se falar isolada e te e u a fa eta espe ial da questão - a sexualidade - u a vez que esta é ape as u a das po tas apare tes desse e ara hado de fios.
\end{abstract}

\section{UMA VISÃO HISTÓRICA E SOCIAL}

adoles ia o o fase be ar ada de tra sição e tre a i fâ ia e a idade adulta já surgiu e desapare eu várias vezes a história da hu a idade. De fato i s rições u eifor es esopotâi as datadas do $28^{\circ}$ sé ulo a.C. os traze re la ações e la e -

1. Preside te da sso iação Brasileira das $\mathrm{E}$ tidades de ssist ia à doles ia.

2. Coorde adora do Progra a de ssist ia Médi a e Psi osso ial à doles ia.

* Por u a questão de pagi ação a segu da parte deste trabalho i titulada "O

Exer í io da exualidade a doles ia. II. Edu ação exual" será publi ada o próxi o ú ero desta Revista.

$\begin{array}{lll}\text { Re ebido e } & 06.06 .90 & \text { provado e } \quad 25.06 .90\end{array}$ 
tos sobre a conduta da juventude que nos parecem absolutamente atuais; é até curioso constatar que o chamado "choque de gerações", isto é, incompreensão mútua entre jovens e adultos ou velhos, nada tem de novo.

Observa-se que a adolescência, como fase problemática de transição, surge cada vez que um grupo social atinge um nível elevado de bem-estar material, de maneira que os pais possam permitir a seus filhos uma formação mais prolongada, sem participar da força de trabalho. Assim, a adolescência como período bem caracterizado surgiu na Mesopotâmia, na fase áurea da Grécia, no período do apogeu de Roma, durante a Renascença, etc. Em períodos históricos nos quais as condições de vida são mais adveras (na Idade Média, durante grandes guerras, etc.) essa fase se retrai e por vezes desaparece, passando o ser humano do final da infância para a fase adulta quase que sem a transição da adolescência. Esse mesmo processo pode ser observado, de certo modo, em uma única época histórica, dependendo do segmento social considerado. Mesmo em nossos dias podemos ver claramente que a maturação psicossocial é mais acelerada nos jovens provenientes de famílias economicamente menos bem situadas. Os jovens de nível econômico-cultural mais baixo, de fato, já no final da infância começam a contribuir com o orçamento familiar, vendendo coisas em esquinas, e até, por vezes, cometendo pequenos furtos. Esses jovens, sem dúvida, adquirem características de adultos precocemente, por serem lançados na chamada "luta pela vida" mais cedo, conseguindo prover sua própria subsistência. Se essa maturação, assim precoce, é saudável ou não, é outro problema; o fato é que ela ocorre. Não é à toa que em países em que o padrão de vida é melhor, por exemplo, nos Estados Unidos, o Comitê de Adolescência da Academia Norte-Americana de Pediatria considera como limite superior dessa fase a idade de 25 anos, enquanto a Organização Mundial de Saúde recomenda que seja considerado adolescente o indivíduo com até 20 anos de idade.

Por isso, ao nos referirmos à sexualidade do adolescente é importante que deixemos bem claro não só o período histórico ao qual nos referimos, mas também de qual segmento social estamos tratando. Dentro do contexto citado de interações biopsicossociais na adolescência, ficam nítidas as diferentes manifestações da sexualidade; é claro que jovens favelados, cujo principal problema é saber o que comer amanhã, vivenciam-na de maneira diversa daquele jovem de classe economicamente elevada, cujo maior problema é conseguir um aumento de mesada com os pais.

Finalmente, antes de iniciar a análise propriamente dita do comportamento sexual do adolescente, importa lembrar que a ado- 
lescência é uma experiência pessoal e única. Embora os fatores condicionantes possam ser semelhantes ou até idênticos, as diferenças entre cada ser humano se manifestam, fazendo com que o vivenciar dessa fase seja peculiar a cada pessoa. Além disso, a adolescência não é uma fase de vida isolada, solta no espaço e no tempo. O jovem convive num mundo, numa época e num meio social que é compartilhado com crianças e com adultos. É importante, por isso, que tenhamos clara uma visão geral do mundo atual.

\section{ALGUNS DOS PROBLEMAS DE NOSSA ÉPOCA}

Não se pode negar que a civilização humana, neste fim de século, está vivenciando uma situação de crise, que se manifesta em várias frentes; vivemos uma época de crise dos valores morais e éticos, crise econômica e política, etc.

Essa situação é resultante de um sem número de fatos ocorridos em nossa história longínqua ou recente, que condicionaram o surgir da atual fase. Claro que, a gosto do analista, pode-se pinçar este ou aquele acontecimento e listá-lo como de fundamental importância. Alguns deles, entretanto, são tão relevantes que não podem deixar de ser considerados.

Um rude golpe foi desferido sobre o amor próprio da Humanidade quando se tornou evidente que a teoria heliocêntrica, proposta por Copérnico, era a mais aceitável. Até então, o Homem julgava habitar o centro do Universo, e a perda dessa posição trouxe-lhe evidente desconforto.

Outra grande frustração foi provocada quando, após décadas de intolerância a incompreensão, os pontos básicos da teoria proposta por Darwin passaram a ser aceitos, ao menos pela maioria das pessoas. O Homem teve que conformar-se então com o fato de, além de não ser seu planeta o centro do Universo, ele mesmo não se constituir num ser especial, mas de fazer parte de um grupo de organismos com as mesmas características. É claro que dentro do reino animal o Homem apresenta características especiais, que fazem dele uma criatura à parte; o fato porém de ser parte integrante de um grupo - o de mamíferos - tirou dele boa parte da ilusão.

Finalmente, não podemos deixar de referir a frustração provocada pelas teorias de Freud e seus discípulos. De fato, dentro dessa linha, o próprio reconhecimento de que muitas de suas atitudes e de seus atos são ditados pelo inconsciente fez com que até a crença humana de ser totalmente racional ficasse abalada.

Essas grandes decepções sem dúvida provocaram mudança no 
autoconceito e na maneira de proceder do Homem, que teve de reformular uma série de posições: deixou de ser o centro do Universo e uma forma única e especial de vida e, até certo ponto, nem mesmo é detentor da capacidade racional de fazer escolhas. As conceituações filosóficas e religiosas da Humanidade sofreram um abalo. Possivelmente a grande onda de misticismo que vem se desenvolvendo em nossos dias é, ao menos em parte, conseqüência desse abalo.

A essas mudanças veio somar-se, perto da metade de nosso século, uma enorme instabilidade capaz de comprometer, além da existência do indivíduo, até mesmo a própria existência da espéçie, da vida, e do planeta: foi o surgir da Era Atômica. Sempre existiram, na história da Humanidade, alguns homens mais poderosos que outros, desde que os hominídeos começaram a se organizar em agrupamentos que seriam o núcleo das civilizações humanas. Entretanto, esse poder, mesmo quando de vida ou de morte, era restrito a alguns comandados, a dezenas ou até, em situações muito especiais, alguns milhares de pessoas. Com o novo armamento, no entanto, alguns poucos homens tornaram-se detentores de um poder capaz de destruir toda a humanidade e até mesmo todas as formas de vida do planeta. $\mathrm{O}$ fato de existirem tais pessoas, e isso ser de conhecimento comum a todos, gerou uma notável instabilidade social, pela incerteza do "se" e do "quando" tal destruição pode acontecer. A sensação de ter havido muito maior progresso técnico e material do que maturação ética e moral da espécie em nada contribui, sem dúvida, para a segurança do homem moderno. Sabemos todos da existência de algumas pessoas, civis ou militares, capazes de lançar a humanidade numa guerra suicida; pouco ou nada sabemos, entretanto, sobre essas pessoas. Serão equilibradas? Estarão à altura de exercer esse poder?

E quanto aos problemas ligados à degradação do meio ambiente, que faremos? Os ecologistas prevêem catástrofes, mas a sociedade como um todo ainda não está sendo capaz de mobilizar-se de maneira eficiente para resolver o problema. Resta ao indivíduo apenas a possibilidade de se preocupar e se intranqüilizar.

Outro fator de instabilidade emocional a social é a rapidez com que as coisas têm se modificado. Para ficarmos apenas no campo das conquistas técnicas, de mais fácil avaliação, lembremos que entre a descoberta dos princípios da fotografia e sua utilização, como recurso acessível, decorreu um intervalo de 112 anos (1727-1839); o mesmo intervalo, para o telefone, foi de 56 anos; para a televisão, de 12 anos; e, para o transístor, de cinco anos. Hoje, as últimas novidades em microcomputação estão disponíveis no merca- 
do consumidor poucos meses após sua descoberta. Os bens materiais saem de moda tão rapidamente que todos nós temos tido a triste experiência de ao acabarmos de pagar um eletrodoméstico (vídeo, liqüidificador ou qualquer outro) já está ele superado, havendo modelos melhores e mais sofisticados disponíveis no mercado. Com a mesma rapidez são "consumidos" ídolos artísticos; os cantores, por exemplo, de que os mais velhos se recordam (Sinatra, Gardel, e outros), e que ficavam anos ou até décadas nos maravilhando com sua arte, já não têm mais similares. Os ídolos musicais do momento têm efêmera duração e seus nomes são freqüentemente esquecidos em poucos meses. Modas, vestuários, teorias filosóficas ou científicas, modelos de comportamento, etc., seguem o mesmo caminho, o que provoca no homem comum uma sensação de transitoriedade e mutabilidade extremas.

A segunda metade de nosso século vem assistindo também um acelerado processo de urbanização, como nunca se viu antes na história da Humanidade. A América Latina, por exemplo, há curtos 20 anos, tinha apenas três de cada 10 de seus habitantes residindo em cidades. Por um processo social complexo, a mesma região tem hoje sete de cada 10 habitantes como moradores urbanos. Grandes cidades, com mais de um milhão de habitantes, são cada vez mais comuns, chegando alguns centros, como São Paulo, à incrível concentração de 5.689 habitantes por quilômetro quadrado! É claro que esse intenso processo de urbanização não se fez exclusivamente à custa de crescimento reprodutivo dos urbanicolas, mas também a migração campo-cidade teve importante papel.

A urbanização acentuada teve sérias conseqüências no estilo de vida das pessoas. Os grandes problemas urbanos (transporte, moradia, segurança) se agudizaram, roubando boa parte do tempo outrora destinado ao lazer. As pessoas tendem a se ensimesmar, cultivando círculo de amizades cada vez menor; não é incomum que não saibamos sequer o nome de nosso vizinho do apartamento ao lado, com quem privamos exclusivamente o uso do elevador entre comentários superficiais sobre o clima.

A própria constituição das famílias mudou. Daquela família extendida, em que conviviam no mesmo espaço três ou mais gerações, com grande número de indivíduos e vários colaterais e "agregados", passou-se à família nuclear, em que convivem apenas os pais e um ou dois filhos, que freqüentemente apenas se vêem rapidamente na maioria dos dias. Essa mudança da estrutura familiar afrouxou os laços de união entre seus membros e trouxe, como conseqüência, a quase total abolição da transmissão de conhecimentos, tradições e costumes entre as gerações. Festividades outrora muito comemo- 
radas, como as festas juninas, as reuniões por ocasião do Natal, etc., vêm cada vez mais sendo esquecidas. Tradições regionais e familiares são quase abandonadas, a ponto de não se conseguir distinguir, já na primeira geração, os descendentes de nordestinos dos de gaúchos. Costumes como o aleitamento materno, por exemplo, que eram familiarmente valorizados de geração a geração, estão em grande parte abandonados pela falta do aprendizado de sua importância. Nossa "civilização moderna" chega ao requinte de tornar necessária a instituição de cursos, visando ensinar fêmeas de mamiferos a amamentar!

O último, mas não menos importante fator modificador da sociedade, é constituído pelos meios de comunicação de massa. Nosso século, que assistiu em suas primeiras décadas um enorme passo na rapidez da divulgação das notícias e dos modismos com a vulgarização da telefonia e do cinema, foi atingido, nas décadas de 20 a 40, em cheio pelos efeitos dos veículos de radiodifusão, e pela televisão, a partir da década de 40 nos países desenvolvidos e na década de 50 no Terceiro Mundo. Nunca antes na história a Humanidade tinha se defrontado com tão poderoso veículo, aperfeiçoado na qualidade da imagem com as transmissões a cores e no alcance com o uso de satélites geoestacionários. Podemos hoje, confortavelmente instalados nas salas de nossas casas (ou até na cama!), assistir às nítidas imagens de fatos que estão ocorrendo ou que ocorreram há poucos minutos em qualquer parte do mundo. Esse aperfeiçoamento técnico tem tornado realidade o conceito de "aldeia global", explicitado por teóricos das comunicações.

O grande problema com a televisão moderna, como soe acontecer com qualquer outro veículo, é o uso que dela se faz. Os meios de comunicação, em si, não são bons nem maus; ocorre apenas que a televisão, se mal utilizada, tem maior potencial em causar danos devido a sua ímpar capacidade de penetração. O fato é que os meios de comunicação de massa, notadamente a televisão, podem e freqüentemente são utilizados para induzir comportamentos.

Todos nós, em grau maior ou menor, sofremos um contínuo processo de indução de atitudes, alterações de hábitos e formação de opiniões, conseqüentes à influência dos meios de comunicação. No tocante aos hábitos de consumo, por exemplo, somos constantemente bombardeados com mensagens que tentam (e às vezes conseguem) nos orientar para o uso da pasta dentifrícia " $x$ ", da maneira de vestir-se "y", ou da opinião "z" sobre o candidato "w". Temos sempre a consciência de estarmos sendo manipulados por técnicas de "marketing" em suas várias formas, eventualmente até de maneira sub-liminar, como é o caso do "merchandising" feito em novelas. 
É claro que a televisão não é o único veículo utilizado na manipulação das massas. Do out-door ao rádio, da revista semanal ao teatro, do cinema ao jornal, todos têm sua parcela de participação. A televisão, entretanto, por ser acessível, atraente a inteligível a quase todos - até aos analfabetos - é sem dúvida o mais importante.

Assim, conforme o exposto, nossa sociedade padece de várias formas de insegurança, que se reflete em todos os níveis de relação intra e interpessoal. Dentro desse contexto, reflete-se também nos adolescentes.

Estes, além dos fatores genéricos de insegurança já abordados, têm ainda seus próprios fatores, inerentes a essa fase de transição. O luto pela perda do corpo infantil e pela perda dos pais da infância, o desconhecimento de suas próprias potencialidades e vários outros fatores são geradores, nessa fase da vida, de instabilidade emocional. Podemos dizer que, dentro da relativa insegurança que a vida moderna nos trouxe, os adolescentes são os que carregam um maior quinhão. Não é de estranhar, por isso, que atuem dentro de modelos considerados pouco comprensíveis pelos adultos.

\section{FATORES ESTIMULADORES DO EXERCÍCIO DA SEXUALIDADE}

Se, grosso modo, aceitarmos a recomendação da Organização Mundial de Saúde e considerarmos que a adolescência fica compreendida na segunda década de vida, podemos ter uma idéia do número de adolescentes em nosso meio consultando as estatísticas oficiais, que indicam que a população brasileira, nessa faixa etária, está perto dos 35 milhões de indivíduos, ou seja, cerca de um quarto do total de habitantes do Brasil. Por outro lado é muito mais difícil avaliar numericamente, mesmo com baixo grau de precisão, quantos desses adolescentes vêm exercendo vida sexual ativa. As estatísticas existentes são apenas regionais, e mesmo assim padecem de precisão por uma série de fatores que tornam difíceis avaliações desse tipo. Indiretamente, pelas conseqüências - gestações, abortos, doenças sexualmente transmissíveis - podemos estimar ser grande esse contingente. No momento, entretanto, qualquer estimativa é aleatória. Dados de outros países, como os Estados Unidos da América, mostram que $10 \%$ das jovens referem experiências sexuais antes dos 13 anos, cifra que sobe para $25 \%$ aos 15 anos. Parece-nos que o número de jovens com vida sexual ativa no Brasil deve ser bem próximo deste; de fato, trabalhos realizados com puérperas adolescentes 
mostram que entre jovens mães de 12 a 20 anos o primeiro coito ocorreu em torno dos 15 anos em $73 \%$ das vezes.

$\mathrm{Na}$ realidade, o exercício da sexualidade entre adolescentes não é uma invenção de nossa época; há apenas duas ou três gerações era hábito comum que nossas avós se casassem aos 14,15 ou 16 anos. O que se tornou característico, há cerca de três décadas, foi a prática da sexualidade por jovens de sexo feminino em condições pré-conjugais. Esse tipo de sexualidade não bem aceita socialmente é que gerou uma série de problemas pessoais, familiares e sociais que ainda não resolvemos.

Os fatores que, nas últimas décadas, têm aumentado a incidência de relacionamento sexual de adolescentes são múltiplos e complexos, sendo difícil avaliar, em cada caso, qual a importância relativa de cada um deles. Alguns, entretanto, merecem destaque.

$\mathrm{Na}$ área social, sem dúvida, a revolução de costumes iniciada no final da década de 50 e intensificada na de 60 ocupa lugar de relevo. Movimentos de contestação, visando dar aos jovens oportunidades de maior participação na tomada de decisões da sociedade (movimentos "beat", "hippie" e outros), atingiram de forma explosiva a estrutura moral e o comportamento da época. Partindo da premissa de que tudo o que fora aceito até então estava errado, promoveu-se a derrubada dos velhos valores, estabeleceram-se novos hábitos e novos padrões de comportamento, inclusive sexual.

Os meios de comunicação de massa passaram a usar a abusar da sensualidade e do erotismo na publicidade dos mais diversos produtos, sempre associando essa erotização à juventude. Divulgou-se, a partir de então, a imagem da "jovem liberada" como sendo aquela que faz sexo quando e com quem quiser, omitindo-se nessa mensagem a possibilidade de optar por não fazer sexo. O próprio grupo social freqüentado pela adolescente passou a estimulá-la a manter uma vida sexual, que se tornou então quase que compulsória. Não se chega a explicitar claramente, mas a imagem passada é a de que para uma jovem chegar virgem ao casamento é por que há qualquer coisa errada com ela.

Obedecendo ao caráter cíclico que marca as manifestações do pensamento e das atitudes humanas, esses padrões vêm sofrendo uma nova tendência de reversão, nos últimos anos. Já se está notando, embora ainda em percentuais minoritários, uma maior valorização da virgindade. O padrão anterior, entretanto, de "liberação", ainda é predominante em todas as camadas sociais.

Outro fator social a estimular o relacionamento sexual pré-conjugal é a tendência de ser cada vez mais elevada a idade à época do casamento. A sociedade atual, extremamente competitiva, leva jovens 
de ambos os sexos - em especial nas classes sociais média e alto - a uma formação mais prolongada, para que tenham melhores condições de enfrentar um mercado de trabalho hostil e possam ter condições mínimas de independência financeira. Por outro lado, observa-se ser cada vez mais precoce o surgimento da primeira menstruação (menarca), por causas ainda não muito claras. De fato, desde que se dispõe de estatísticas médicas confiáveis - cerca de 150 anos - tem-se verificado que as menstruações se iniciam aproximadamente 10 meses mais cedo a cada geração, ocorrendo hoje por volta dos 12 anos e 6 meses, em média. Sabendo-se que a menarca é uma decorrência de níveis elevados de esteróides sexuais de origem ovariana, pode-se afirmar que nossas jovens estão ficando biologicamente aptas para a reprodução, e portanto para o exercício da sexualidade, cada vez mais precocemente.

Aliam-se os dois fatores. O intervalo entre o preparo biológico para a sexualidade (menarca) e a permissão social para exercê-la (casamento) vai ficando cada vez mais longo, o que sem dúvida estimula o exercício pré-conjugal da sexualidade.

Cabe ainda considerar algumas das características emocionais da adolescência. Nessa fase da vida, a sexualidade torna-se forte fator motivador a permeia todas as atividades e os pensamentos. O sexo torna-se o assunto predileto de conversa, o ponto principal das preocupações e o script mais freqüente dos sonhos. O adolescente, que sempre prefere fazer a planejar, tem enorme dificuldade em adiar a realização de seus desejos; além do estímulo do grupo, os jovens têm grande curiosidade de experimentação e premente necessidade de testar-se, o que os leva a arriscarem-se a provar o novo, sem o temor das conseqüências.

\section{INICIAÇÃO SEXUAL}

Foi-se o tempo em que a iniciação sexual do rapaz era feita mais freqüentemente com prostitutas e a da moça predominantemente com o marido ou, no máximo, com o noivo. A prostituição hoje - principalmente após o advento do temor à AIDS - é uma instituição reservada a adultos solitários ou, menos freqüentemente, a pessoas que buscam o insólito e o incomum, como espetáculos eróticos, protituição masculina, etc. Como iniciação sexual de rapazes, a prostituição é atualmente pouco freqüente. Na maioria das vezes a iniciação sexual de adolescentes tem sido feita aos pares, ocasionalmente até poucos dias após o início do namoro. As vantagens da maravilha da descoberta a dois são, freqüentemente, empanadas 
pelas desvantagens advindas da mútua inexperiência, além das condições adversas em que essa iniciação habitualmente ocorre.

Quanto a essa primeira experiência sexual, algumas palavras devem ser ditas a respeito da expectativa que a cerca. Nossa sociedade, através dos meios de comunicação, tem feito uma verdadeira apoteose do orgasmo. A idéia transmitida a crianças, adolescentes e até a mulheres adultas, através principalmente das chamadas "revistas femininas" é de que o orgasmo é a meta fundamental da existência, sendo ensinado em programas de TV e em artigos de revistas as maneiras mais seguras de alcançá-lo e dele desfrutar. Passa-se a imagem de que o orgasmo é uma obrigação e que a relação em que ele não é alcançado é francamente patológica.

Nossos casais de adolescentes, mal conhecendo a si próprios quanto mais ao parceiro --, iniciam uma relação na qual, segundo eles julgam, ficará fatalmente determinado o grau de masculinidade ou de feminilidade de cada um. Ambos estão nervosos, inseguros e ansiosos por experimentar o tal "orgasmo", apregoado como a mais maravilhosa das sensações, durante o qual se ouve música de sinos e se vê estrelas. É claro que o casal - principalmente a mulher - de inexperientes, que não conhece suas áreas erógenas e não sabe como intensificar a excitação, e que freqüentemente está tendo um relacionamento clandestino, com medo de ser surpreendido, se frustra. É fato comum, em ambulatórios de atendimento a adolescentes, ouvir referências a iniciações sexuais desagradáveis, quando não traumatizantes.

Para os adolescentes de sexo masculino a situação é também problemática. Dentro da estrutura machista de nossa sociedade, espera-se sempre que o homem tenha maiores conhecimentos sobre sexualidade, esquecendo-se com freqüência que as dúvidas existenciais e as dificuldades de auto-afirmação são comuns aos dois. Exige-se do jovem, sob pena de machucar sua auto-estima, que ele seja um expert em técnicas e táticas sexuais. O homem, neste contexto machista, deve estar disposto a ter relações com o maior número possível de mulheres, estando sempre pronto para qualquer parceira e a qualquer hora, sob pena de ser ridicularizado.

É claro que esse estado de prontidão para a ereção não existe, mas o reconhecimento disso requer uma maturidade para vencer preconceitos que os jovens não têm. Essa situação gera uma angústia mal declarada e mal compreendida que seguramente participa da gênese do elevado número de disfunções sexuais masculinas encontrado em adultos.

O temor do insucesso e a angústia de auto-avaliar constantemente o próprio desempenho, sem dúvida, contribuem para que a 
iniciação sexual dos rapazes seja também experiência menos valiosa do que deveria.

\section{LOCAL DA INICIAÇÃO SEXUAL}

Pesquisas recentes, realizadas em São Paulo, mostram ocorrer a iniciação mais freqüentemente na casa dos pais do rapaz. Tfnhamos a idéia, predominantemente adulta, de que a iniciação sexual ocorreria em automóveis, drive-in ou em motéis. Raciocinando após conhecer os resultados desse estudo, entretanto, encontramos bastante lógica neles, visto serem esses locais, por nós supostos como freqüentes, de difícil acesso ou caros demais para a média dos adolescentes. Na residência da família da moça, por outro lado, a vigilância sobre o par de namorados é naturalmente muito intensiva, pois os gravames da vida sexual ativa são mais pesados para a mulher.

\section{FAIXA ETÁRIA}

No tocante à época de ocorrência da primeira relação em mulheres adolescentes, a maioria das pesquisas aponta para a faixa de 15 a 17 anos, que seria o período de maior risco. As que não mantêm relações até os 17 anos, de maneira geral, vão iniciar sua vida sexual após os 20 anos, ou seja, já em idade adulta. Para os rapazes a iniciação é mais tardia, dos 17 aos 20 anos, até porque em nossa sociedade as mulheres de qualquer faixa etária são mais freqüentemente atraídas por homens um pouco mais velhos. Nossa sociedade não vê com bons olhos um relacionamento no qual a mulher tenha mais idade e esse preconceito, embora não tenha em si qualquer razão lógica, é partilhado também pelas adolescentes.

\section{NÚMERO DE PARCEIROS}

Outro conceito pré-formado que a maioria dos adultos alimenta é sobre a promiscuidade sexual dos adolescentes. Em alguns levantamentos por nós realizados ficou patente que o relacionamento sexual da jovem com vários parceiros praticamente inexiste. De maneira geral, a adolescente tem um namorado que é seu parceiro sexual fixo, sendo muito raros os casos em que se constatam "infidelidades". Ocorre na adolescência, com alguma regularidade, a 
troca de namorados após um certo período de tempo, configurando a situação denominada de "monogamia seriada". A imensa maioria das adolescentes estudadas, em várias pesquisas realizadas nos últimos anos, referia ter tido relações com um, às vezes dois ou muito raramente três parceiros, apesar de muitas delas estarem há vários anos mantendo vida sexual ativa.

\section{CONSEQÜÊNCIAS DO EXERCÍCIO DA SEXUALIDADE POR ADOLESCENTES}

Do ponto de vista do rapaz, as últimas décadas só trouxeram de novo, na área da sexualidade, as oportunidades de relacionamento com jovens, em busca de prazer mútuo. Na realidade, historicamente, a iniciação sexual do homem tem sido feita na juventude, em fase pré-conjugal. Mesmo na época anterior à "revolução sexual", nas décadas de 40 e 50, por exemplo, a imensa maioria dos homens tinha experiência sexual prévia, quando do casamento. A única "novidade", com o advento da maior liberação sexual, foi quanto ao tipo e ao número de parceiras disponíveis. Para as moças, entretanto, a mudança foi radical.

As conseqüências psicológicas positivas da antecipação da vida sexual ativa para o período pré-conjugal em adolescentes de sexo feminino ainda são de difícil avaliação, pela falta de perspectiva que caracteriza a análise dos que, como nós, ainda estão muito próximos e emocionalmente envolvidos nesse processo para poder julgar com isenção; afinal, é de nossas irmãs e de nossas filhas de quem estamos falando. Faz-se mister que esperemos ainda algum tempo para que se possa julgar desapaixonadamente se o fato de iniciar a vida sexual ativa mais precocemente fará dessas adolescentes seres humanos melhores e mais felizes do que as das gerações precedentes. Infelizmente, embora essa conclusão não tenha a pretensão de ser definitiva, parece que não é assim.

A experiência em ambulatórios de atendimento de adolescentes vem mostrando que o mais comum exercício da sexualidade não tem contribuído para a maior realização das jovens, como pessoas. Aferindo apenas os aspectos emocionais - as conseqüências orgânicas serão analisadas a seguir - não temos encontrado nessas jovens, nem nas adultas que viveram recentemente sua adolescência, uma menor incidência de disfunções sexuais, um maior ajuste emocional ou um maior grau de felicidade. Embora o exercício da sexualidade em si pudesse, em teoria, facilitar o ajuste interpessoal e até o intrapsíquico, parece ser na motivação pessoal que se encontra 
o engano. A imensa maioria das adolescentes inicia sua vida sexual por modismo, por auto-afirmação, para não "perder" o namorado, ou por outros motivos menores. São raras as que conseguem ter uma visão positiva da sexualidade, compreendendo-a como um bem, como uma forma de aprofundar um relacionamento afetivo, como maneira de buscar e dar prazer sem machucar o parceiro nem a si mesma. A imensa maioria das jovens age como se não conhecesse ou não quisesse conhecer - sequer as possíveis conseqüências negativas da prática sexual.

Do ponto de vista estritamente somático, a sexualidade como vem sendo exercida pelos adolescentes de ambos os sexos tem aspectos altamente negativos.

O grande incremento da freqüência de moléstias sexualmente transmissíveis é uma delas. Doenças, como a sífilis, por exemplo, consideradas praticamente extintas, ressurgiram a recrudesceram a partir da década de 60 . Moléstias com alto potencial de morbidade, como a gonorréia, tornaram-se extremamente comuns. A sensação de impunidade e invulnerabilidade, típico resquício do "pensamento mágico" infantil que ainda sobrevive na adolescência, faz com que os jovens ignorem e desprezem as medidas profiláticas e o tratamento precoce.

Outra conseqüência orgânica negativa do exercício da sexualidade na adolescência é o incremento observado no número de gestações indesejadas. Desconhecendo até mesmo fatos rudimentares de anatomia e da fisiologia sexual, sem meios para adquirir instrução anticoncepcional adequada e "enfrentando preconceitos, as jovens acabam se valendo de leituras mal compreendidas ou de conselhos desinformados de outras adolescentes. O rapaz, dentro do esquema machista de nossa sociedade, freqüentemente se omite ou se recusa a participar da anticoncepção. Como resultado, observou-se nas ultimas três décadas um assustador aumento do número de jovens adolescentes grávidas e do número de abortamentos provocados.

Estabelecida a gestação, o problema passa a ter intenso cunho social. Além do risco de ser expulsa da casa paterna ( $5 \%$ das vezes, em nosso material), com conseqüente quase certo ingresso na prostituição, a jovem passa a viver um imenso drama, pois as soluções possíveis para a situação são todas más. A opção pela interrupção da gravidez, pelo abortamento provocado, traz elevado grau de risco físico e psíquico. O casamento forçado com o parceiro sexual, apesar de ser solução do agrado de boa parte dos pais, freqüentemente conduz a casamentos mal estruturados, em que a separação ocorre por vezes até antes do nascimento da criança. Ser mãe solteira adolescente é uma situação que traz em si um enorme ônus social, com 
sérias conseqüências presentes e futuras; e depois, o que fazer do nenê? Criá-lo? Oferecê-lo à adoção? Enfim, depois de estabelecida a gestação, as soluções possíveis são sempre precárias e potencialmente danosas para a adolescente, para a famífia e para a sociedade.

Assim, como vimos, as consequências psicológicas, sociais e orgânicas do exercício da sexualidade na adolescência são, de maneira geral, negativas.

As propostas para a solução do problema, em especial quanto ao estabelecimento de um esquema eficaz para a educação sexual, serão analisadàs no próximo número desta Revista. 